\title{
Urban effect on the characteristics of cloud-to-ground lightning over Belo Horizonte-Brazil
}

\author{
I. R. C. A. Pinto, O. Pinto Jr., M. A. S. S. Gomes, and N. J. Ferreira \\ National Institute of Space Research - INPE, Av. Astronautas 1758-Jd. Da Granja, Sao Jose dos Campos-Sao Paulo, \\ 12227-010, Brazil
}

Received: 21 February 2003 - Revised: 24 June 2003 - Accepted: 2 July 2003 - Published: 1 January 2004

\begin{abstract}
An 8-year climatological analysis (1989-1996) of lightning network data over Belo Horizonte, a large city located in Southeastern Brazil, and nearby surrounding areas has indicated a significant enhancement of approximately $100 \%$ in the negative flash density and of $50 \%$ in the positive flash density over and downwind of the city, compared with the other adjacent areas. A decrease of $25 \%$ in the percentage of positive flashes was also observed over and downwind of the city. No urban effect was evident in the peak current of both negative and positive flashes. These results are in agreement with the recent results obtained by Steiger et al. (2002) for Houston, except that the strength of the effect is twice larger than in Houston. The reason for this difference is not clear.
\end{abstract}

Key words. Meteorology and atmospheric dynamics (atmospheric electricity; convective processes; lightning)

\section{Introduction}

Westcott (1995) was the first to reveal the effect of several cities on enhancing cloud-to-ground (CG) lightning activity over and downwind of the cities. After that, several recent studies (Orville et al., 2001; Soriano and Pablo, 2002; Steiger et al., 2002; Naccarato et. al., 2003) have confirmed this result. In general, they have attributed the effect to the urban heat island circulation, even though a possible role of air pollution has been suggested. Several authors have found evidence of urban effects on the local weather phenomena (Myrup, 1969; Braham, 1974; Huff and Changnon, 1973; Semonin and Changnon, 1974; Changnon et al., 1981; Landsberg, 1981; Karl et. al., 1988, Balling and Idso, 1989). Steiger et al. (2002) were the first to investigate the urban effect on lightning characteristics, such as the percentage of positive flashes and peak current, based on a 12-year climatological analysis (1989-2000) of the National Lightning De-

Correspondence to: I. R. C. A. Pinto

(iara@dge.inpe.br) tection Network (NLDN) data over Houston, Texas. They have found a decrease of $12 \%$ in the percentage of positive flashes and no significant effect on the peak current of negative and positive CG flashes.

In this paper an 8-year climatological analysis of lightning data was made over the city of Belo Horizonte (approximated geographic coordinates $-20^{\circ} \mathrm{S}$ of latitude and $44^{\circ} \mathrm{W}$ of longitude) and nearby areas. Belo Horizonte is the capital of the state of Minas Gerais and it has about 2.5 million people. Different than Houston, which is located near a coastal area, Belo Horizonte is located in a central area characterized by a mountain terrain. Negative and positive flash density and peak current, and the percentage of positive flashes were calculated. The results are presented and compared to the ones obtained by Steiger et al. (2002). To the best of our knowledge, this is the first long-term study of lightning characteristics over a large city in the tropics.

\section{Lightning data}

The lightning data used in this work was obtained by a LPATS network installed in the state of Minas Gerais, in Southeast Brazil, in 1988. The network operated up to 1996, when a hybrid network of LPATS and impact sensors replaced it. Due to constant changes in the network, data after 1996 were not considered in this study. The data were sorted into blocks of approximately $0.08^{\circ}$ longitude and $0.08^{\circ}$ latitude, corresponding to an approximate resolution of $9 \mathrm{~km}$. Taking into consideration that several studies (see Pinto et al. (1999a, b, c) and references therein) have shown that this type of network is subject to contamination by intracloud flashes, only CG flashes with first stroke peak current larger than $15 \mathrm{kA}$ were considered in this study. Although the contamination by intra-cloud flashes may extend above this threshold, mainly for positive flashes, the above consideration has no influence on the results presented in this paper. Figure 1 shows the location of the sensors and the city 


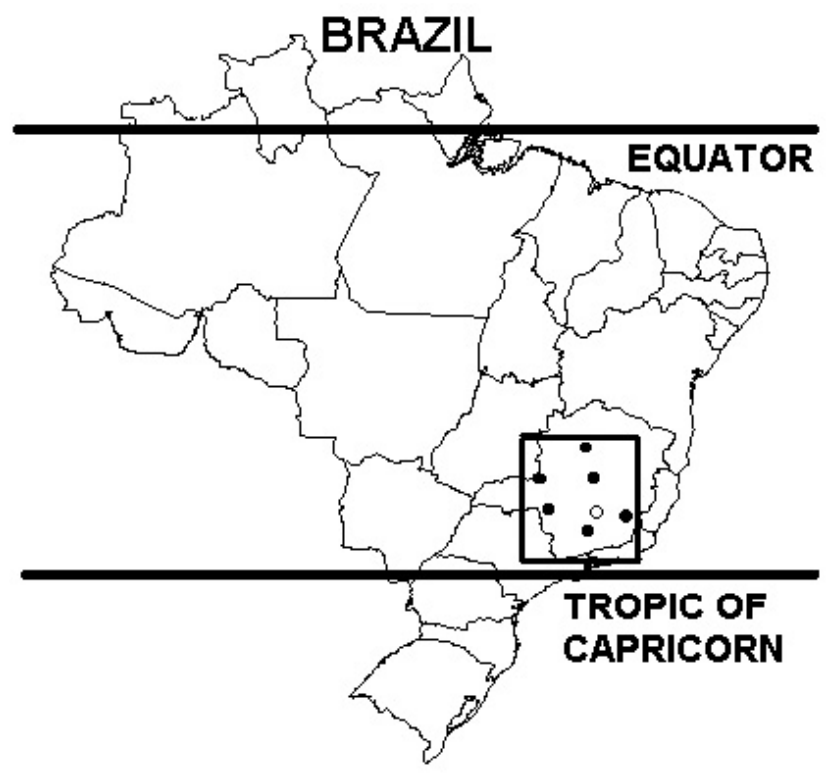

Fig. 1. Map of Brazil indicating the location of the lightning sensors used in this study and of the city of Belo Horizonte.

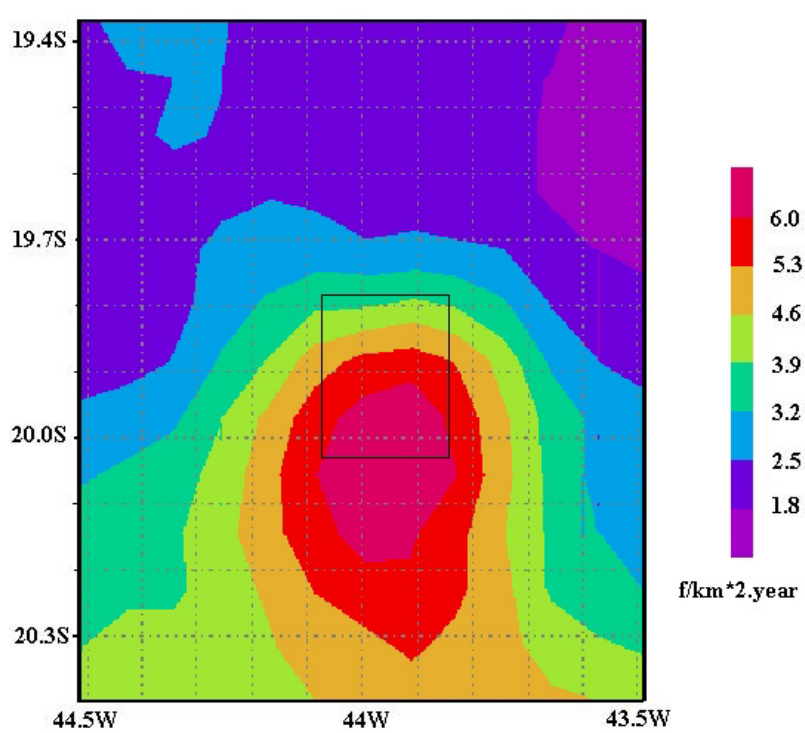

Fig. 2. Eight-year (1989-1996) mean annual negative flash density in flashes $\mathrm{km}^{-2} \mathrm{yr}^{-1}$ centered on Belo Horizonte (indicated by a black rectangle), at a spatial resolution of $9 \mathrm{~km}$.

of Belo Horizonte. More details about the network can be found elsewhere (Pinto et al., 1999a, b, c; Pinto et al., 2003).

\section{Results and discussion}

Figure 2 shows the geographical distribution of the mean annual negative flash density over Belo Horizonte and nearby areas. A large enhancement (approximately 100\%) is evident over and downwind of the city. The prevailing winds

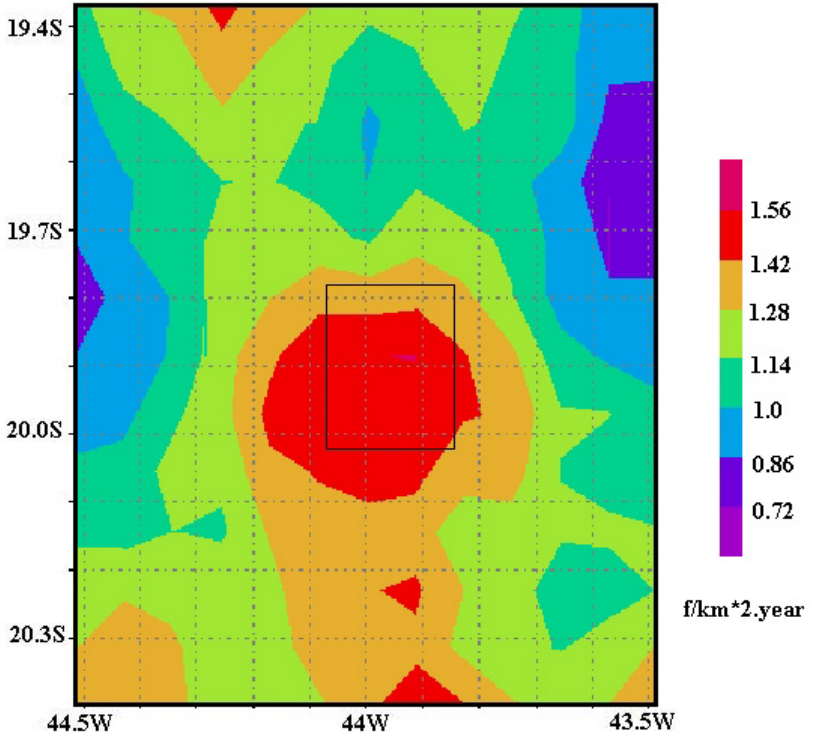

Fig. 3. As in Fig. 2, except for positive flashes.

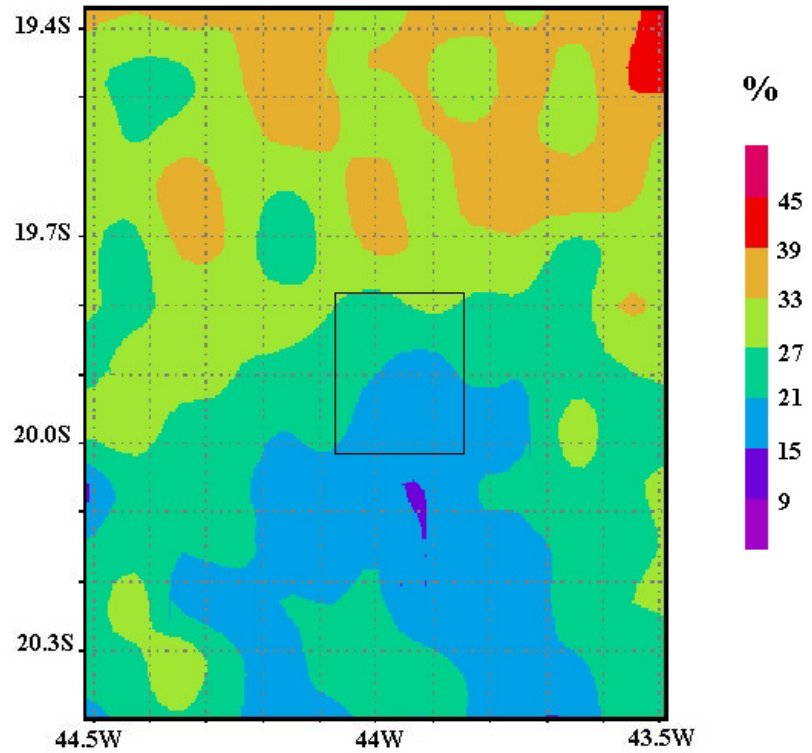

Fig. 4. Eight-year (1989-1996) percent positive lightning centered on Belo Horizonte (indicated by a black rectangle), at a spatial resolution of $9 \mathrm{~km}$.

in the city have a northerly component and hence, upwind (downwind) areas are located to the north (south). Figure 3 shows the same distribution for positive flashes. An enhancement is still evident, although it has lower strength (approximately 50\%) than that in Fig. 2. Considering the total number of flashes, an enhancement of approximately $85 \%$ was observed. This value is larger than that found by Steiger et al. (2002) over and downwind of Houston (45\%), and similar to the maximum value reported by Wescott (1995) for 16 cities in the United States. 


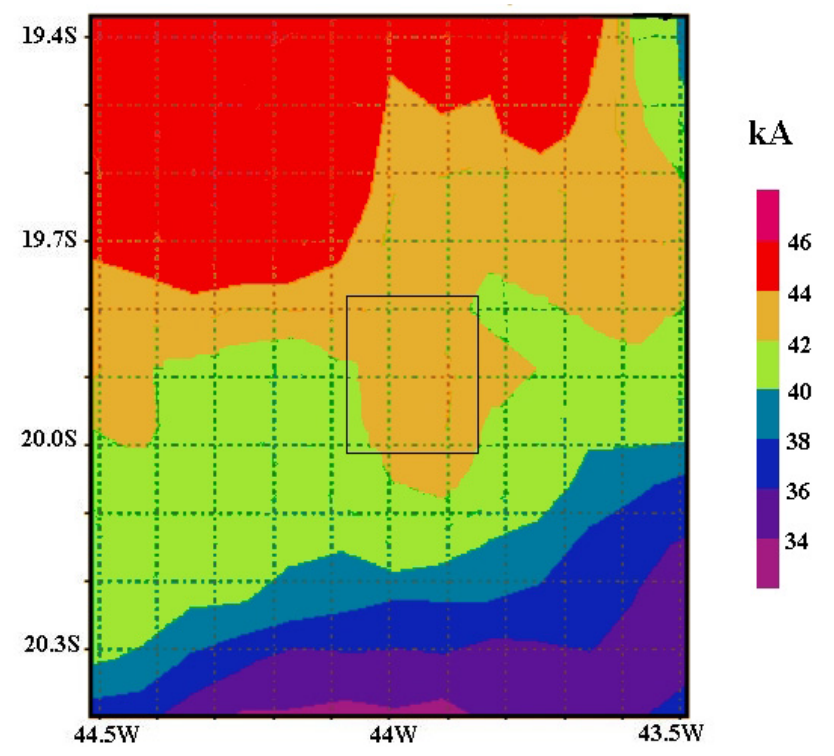

Fig. 5. Eight-year (1989-1996) mean negative peak current in kA centered on Belo Horizonte (indicated by a black rectangle), at a spatial resolution of $9 \mathrm{~km}$.

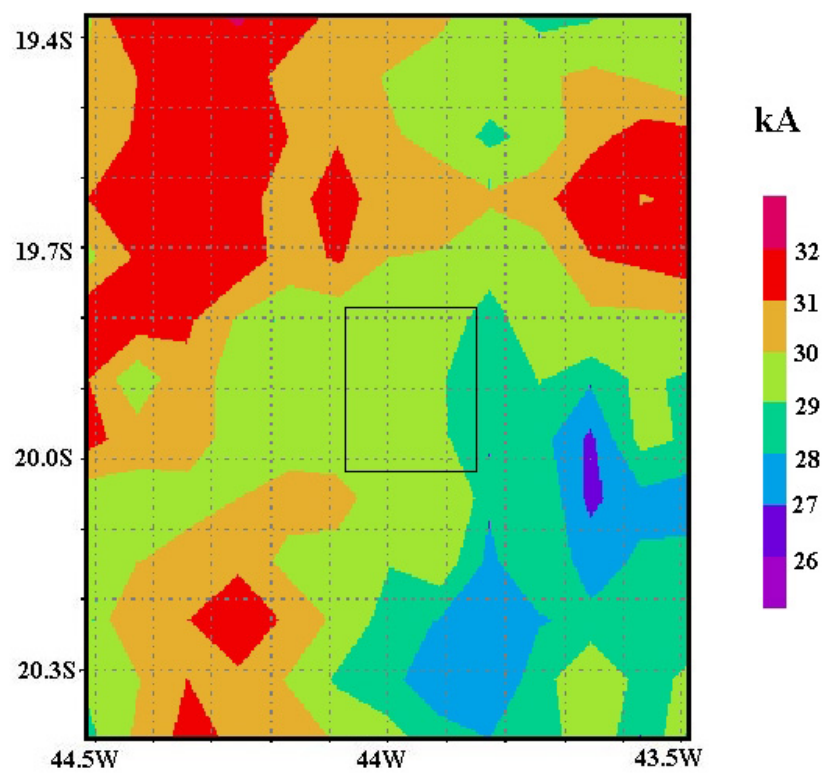

Fig. 6. As in Fig. 5, except for positive peak current.

Figure 4 shows the percentage of positive flashes over Belo Horizonte and nearby areas. The percentage of positive flashes decreases by approximately $25 \%$ over and downwind of Belo Horizonte. This result confirms the previous result obtained by Steiger et al. (2002), who found a decrease of $12 \%$ over Houston. Steiger et al. (2002) have made a comprehensive discussion about the possible explanations for this decrease in percentage of positive flashes. They have found in the literature contradictory hypotheses on how pollution may affect the polarity of CG flashes. Clearly, further observations, such as $\mathrm{CCN}$ distribution and cloud-droplet spectra,

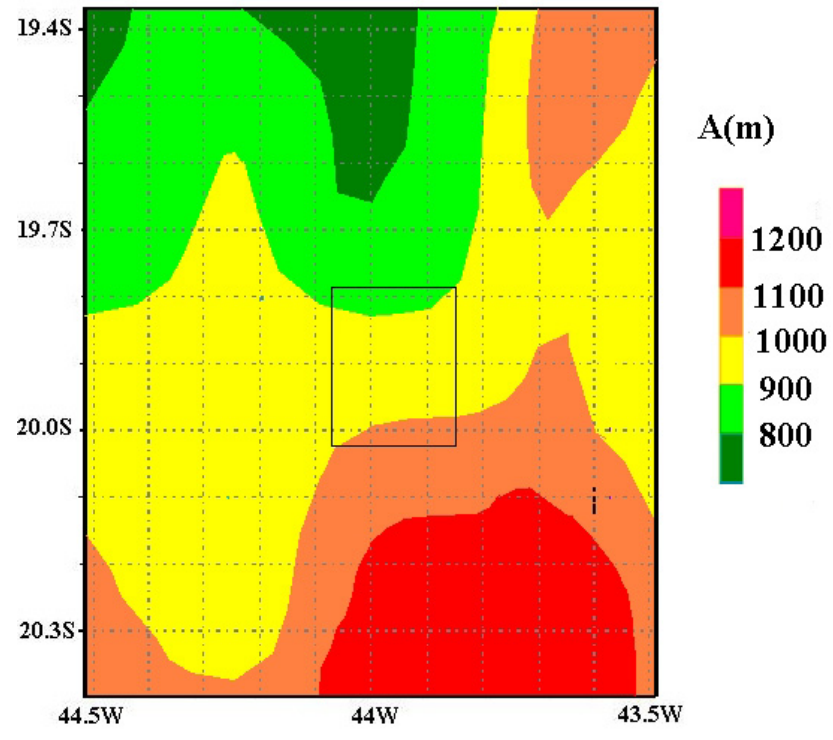

Fig. 7. Mean altitude map in meters centered on Belo Horizonte (indicated by a black rectangle), at a spatial resolution of $9 \mathrm{~km}$.

are required to explain this lightning characteristic pattern.

Figures 5 and 6 show the negative and positive peak current, respectively, over Belo Horizonte and nearby areas. No evidence of an urban effect was found. However, a decrease in the peak current of both polarities is evident southeast of Belo Horizonte, mainly for negative flashes. The decrease in peak current may be related to the higher altitude in this region, as evident in Fig. 7, which shows the average altitude based on the Earth Topographic 5-min Model provided by NOAA. The change of peak current as a function of altitude was first observed by Reap (1986). More recently, Orville and Huffines (1999) have also found evidence of such a relationship.

\section{Conclusions}

In this paper, an 8-year climatological study (1989-1996) of lightning network data in a large city of Brazil was presented. To the best of our knowledge, this is the first long-term study reported in the literature related to the role of urban effect on cloud-to-cloud lightning in the tropics. It has indicated a significant enhancement of approximately $100 \%$ in the negative flash density and of $50 \%$ in the positive flash density over and downwind of Belo Horizonte, a large city located in Southeastern Brazil, compared to the nearby surrounding areas. A decrease of $25 \%$ in the percentage of positive flashes was also observed over and downwind of the city. The strength of the urban effect was higher than in Houston, for a similar study (Steiger et al., 2002). No urban effect was evident in the peak current of both negative and positive flashes, in agreement with the results obtained in Houston.

Acknowledgements. The authors would like to thank the Companhia Energética of Minas Gerais (CEMIG) for providing the 
data, Iara R. N. Andre for supporting in the data analysis and the Conselho Nacional de Desenvolvimento Científico e Tecnológico (CNPq) for supporting this research.

Topical Editor O. Boucher thanks a referee for his help in evaluating this paper.

\section{References}

Balling, R. C. and Idso, S. B..: Historical temperature trends in the US and the effect of urban population growth, J. Geophys. Res., 84, 3359-3363, 1989.

Braham, R. R.: Cloud physics of urban weather modification: a preliminary report, Bull. Amer. Meteor., 55, 100-106, 1974.

Changnon, S. A., Semonin, R. G., Auer, A. H., Braham, Jr., R. R., and Hales, J. M.: METROMEX: a review and summary, Meteor. Monog., 18, Amer. Meteor. Soc., 181, 1981.

Huff, F. A. and Changnon, Jr., S. A.: Precipitation modification by major urban areas, Bull. Amer. Soc., 54, 1220-1232, 1973.

Karl, T. R., Diaz, H. F., and Kukla, G.: Urbanization: its detection in the United States climate record, J. Climate, 1, 1099-1123, 1988.

Landsberg, H. E.: The urban climate, Int. Geophys. Ser., 28, Academic, San Diego, Calif., 275 pp., 1981.

Myrup, O.: A numerical model of the urban heat island, J. Applied Meteor., 8, 908-918, 1969.

Naccarato, K. P., Pinto, Jr., O., and Pinto, I. R. C. A.: Evidence of thermal and aerosol effects on the cloud-to-ground ligtning density and polarity over large urban areas of Southeastern Brazil, Geophys. Res. Lett., 30 (13), 1674-1677, 2003.

Orville, R. E. and Huffines, G. R.: Lightning ground flash measurements over the contiguous United States: 1995-97, Mon. Wea. Rev., 127, 2693-2703, 1999.

Orville, R. E., Huffines, G., Gammon, J. N., Zhang, R., Ely, B., Steiger, S., Phillips, S., Allen, S., and Read, W.: Enhancement of cloud-to-ground lightning over Houston, Texas, Geophys. Res. Lett., 28(13), pp. 2597-2600, 2001.

Pinto, Jr., O., Pinto, I. R. C. A., Diniz, J. H., Carvalho, A. M., Cazetta Filho, A.: Cloud-to-ground lightning flash characteristics obtained in the southeastern Brazil using the LPATS technique and the new hybrid lightning location methodology, Proceedings of the 11th International Conference on Atmospheric Electricity, 62-64 (NASA/CP-1999-209261), 1999a.

Pinto, Jr., O., Pinto, I. R. C. A., Gomes, M. A. S. S., Padilha, A. L., Vitorello, I., Diniz, J. H., Carvalho, A. M., and Cazetta Filho, A.: Cloud-to-ground lightning in the southeastern Brazil in 1993, 1, Geographical distribution, J. Geophys. Res., 104(D24), 31369 31379, 1999b.

Pinto, I. R. C. A., Pinto, Jr., O., Rocha, R. M. L., Diniz, J. H., Carvalho, A. M., and Cazetta Filho, A.: Cloud-to-ground lightning flashes in the southeastern Brazil in 1993, 2, Time variations and flash characteristics, J. Geophys. Res., 104(D24), 31 381-31 387, 1999c.

Pinto, Jr., O., Pinto, I. R. C. A., Diniz, J. H., Cazetta Filho, A., Cherchiglia, L. C. L., and Carvalho, A. M.: A seven-year study about the negative cloud-to-ground lightning flash characteristics in the southeastern Brazil, J. Atmos. Solar-Terr. Phys., 65(6), 739-748, 2003.

Reap, R. M.: Evaluation of cloud-to-ground lightning data from the western United States for the 1983-84 summer seasons, J. Climate Appl. Meteor., 25, 785-799, 1986.

Soriano, L. R. and Pablo, F.: Effect of small urban areas in central Spain on the enhancement of cloud-to-ground lightning activity, Atmos. Environm., 36, 2809-2816, 2002.

Steiger, S. M., Orville, R. E., and Huffines, G.: Cloud-to-ground lightning characxteristics over Houston, Texas: 1989-2000, J. Geophys. Res., 107(D11), 10.1029/2001JD001142, 2002.

Westcott, N. E.: Summertime cloud-to-ground lightning activity around major Midwestern urban areas. J. Appl. Meteor., 34, 1633-1642, 1995. 